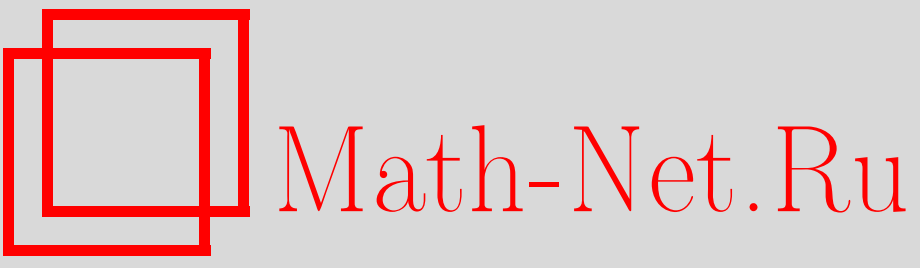

В Санкт-петербургском математическом обществе, УМH, 2002, том 57, выпуск 4, 191-196

DOI: https://doi.org/10.4213/rm551

Использование Общероссийского математического портала Math-Net.Ru подразумевает, что вы прочитали и согласны с пользовательским соглашением

http://www.mathnet.ru/rus/agreement

Параметры загрузки:

IP : 18.234 .156 .22

26 апреля 2023 г., 12:56:09 


\title{
В САНКТ-ПЕТЕРБУРГСКОМ МАТЕМАТИЧЕСКОМ ОБЩЕСТВЕ
}

\author{
ЗАСЕДАНИЯ ОБШЕСТВА
}

\section{Заседание 22 сентября 1998 г.}

Впечатления о Международном конгрессе математиков в Берлине (август 1998 г.)

Выступления участников: А. Н. Бородин, А. М. ВеРшик, С. В. КислякОв, Н. Ю. НЕЦВЕТАЕВ, С. Ю. ПИЛЮГИН, Н. Н. УРАЛЬЦЕВА.

Заседание 13 октября 1998 г. И. А. ПАнин. Сумма четырех квадратов и гипотеза Гротендика.

Рассказана общая формулировка гипотезы Гротендика, касающейся главных однородных пространств, рассмотрены интересные примеры, показана связь этой проблемы с некоторыми задачами о дифференциалах второго рода и с общей гипотезой Герстена. Недавний прогресс тесно связан с идеями из работ Воеводского. В частности, рассказано об уравнении

$$
x^{2}+y^{2}+z^{2}+t^{2}=a
$$

и его решениях над полями рационалшных функций.

Заседание 22 декабря 1998 г. С. В. Кисляков. Операторные пространства и задача о подобии.

В январе 1996 г. Ж. Пизье построил пример полиномиально ограниченного оператора в гильбертовом пространстве, неподобного сжатию. Тем самым был дан ответ на вопрос, сформулированньй на рубеже 50-х и 60-х годов и привлекавший с тех пор значительное внимание. В докладе обсуждался контрпример Пизье, другие (схожие по постановке) задачи о подобии, а также были затронуты связи с возникшей относительно недавно теорией “операторных пространств" и вполне ограниченных отображений.

Заседание 5 января 1999 г. В. А. КАЙмАнович (Rennes, Франция). Символическая динамика, эргодичность коциклов и геометрические приложения.

Задача об эргодических свойствах орициклического потока на компактных поверхностях отрицательной кривизны является классикой эргодической теории. Однако лишь недавно появилось несколько работ о некомпактном случае, а именно, об абелевых накрытиях компактных многообразий. Доклад посвящен новому подходу, разработанному совместно К. Шмидтом и докладчиком. Этот подход основан на изучении групповых коциклов на топологических цепях Маркова и ведет к существенному обобщению ранее известных результатов.

Отчет о заседаниях Санкт-Петербургского математического общества в 1997-1998 гг. помещен в УМН, т. 54, вып. 1. Отчет о деятелшности Санкт-Петербургского математического общества за период с августа 1999 г. по декабрь 2001 г. помещен в УМН, т. 57, вып. 1. 
Заседание 12 января 1999 г. Совместное заседание Секции математики Дома Ученых, Санкт-Петербургского математического общества и Института математики РАН (ПОМИ).

К 100-летию со дня рождения академика В. А. Фока (1898-1974).

С научными сообщениями выступили Л. Д. ФАДДЕЕВ и А. М. ВЕРшиК. С воспоминаниями о В.А. Фоке - Г. И. ПЕТРАШЕНЬ, Ю. Н. ДЕМКОВ, И. В. КОМАРОВ.

Заседание 30 марта 1999 г. А. П. ПЕтухов. Всплески и их приложения.

Под базисами всплесков (wavelet bases) обычно понимают базисы пространства $L^{2}$, получающиеся при помощи некоторого набора двоично-рациональных сдвигов и растяжений (сжатий) аргумента единственной функции. С момента формирования к концу 80-х общих взглядов на построение базисов всплесков круг их применения постоянно расширяется.

В докладе было обсуждено современное состояние дел в этой области и причины такой популярности всплесков в приложениях (теория аппроксимациии, быстрые алгоритмы, сжатие информации и т. д.).

Заседание 13 апреля 1999 г. О.Р. Мусин (Москва). Диаграмма Вороного и триангуляция Делоне.

Диаграммой Вороного множества точек $S$ в евклидовом пространстве назьвается разбиение этого пространства на выпуклше области $V(p)$, где $p$ - точка из $S . V(p)$ содержит все точки пространства, которые ближе к $p$, чем к остальным точкам из $S$. Это понятие появилось еще у Декарта, хотя первые серьезные результаты принадлежат Дирихле и Вороному. Триангуляция (разбиение) Делоне - это разбиение, двойственное к диаграмме Вороного. Эти понятия стали очень популярными в вычислительной геометрии и других прикладных науках.

В докладе приведены основные геометрические свойства этих конструкций, рассказано об алгоритмах их построения (в частности, с использованием понятия "вторичньй многогранник", введенного Гельфандом-Зелевинским-Капрановым) и основные их применения. Кроме того, было предложено многомерное обобшение теоремы о четырех вершинах для многогранников, являющимся подкомплексом триангуляции Делоне.

Заседание 27 апреля 1999 г. И. А. Дынников (Москва). Трехстраничный подход в теории узлов.

Стандартным инструментом в теории узлов являются плоские диаграммы. Диаграмма узла - это его проекция на плоскость, для каждого пересечения на которой указано, какая ветвь проходит сверху, а какая снизу. Классическая теорема Райдемайстера, дающая необходимое и достаточное условие эквивалентности узлов, заданных плоскими диаграммами, сводит задачу классификации узлов и нахождения изотопических инвариантов к сложным задачам комбинаторики и алгебры.

Новый алњтернативный подход состоит в том, чтобы вкладьвать узел или зацепление в объединение трех полуплоскостей с общей граничной прямой. Эти полуплоскости расположены в трехмерном пространстве как три страницы книги.

Трехстраничньй подход приводит к принципиально иной комбинаторике и алгебре. Для кодировки узлов теперь используются слова в некотором универсальном конечном алфавите, а роль классических движений Райдемайстера восполняет некоторый конечньй набор соотношений. Заданная этими соотношениями полугруппа имеет своим центром множество изотопических классов всех зацеплений. Таким образом, классификация зацеплений сводится к проблеме тождества слов в этой полугруппе.

Трехстраничньй подход оказывается полезным для компьютерного распознавания тривиалного узла. Классический алгоритм распознавания (Хакен, 1961 г.) далек от компьютерной реализации для диаграмм с более чем 10 пересечениями. Существуют, однако, частичные алгоритмы распознавания, которые проверяют лишь некоторое достаточное условие тривиальности. Один из таких алгоритмов реализован для диаграмм, имеющих до 50 пересечений (С. Матвеев, Е. Фоминых, 1997 г.). Частичный алгоритм, основанный на трехстраничном подходе демонстрирует фантастическую скорость и резултативность при распутьвании диаграмм тривиального узла, имеющих сотни пересечений.

\section{Европейские лекции по математике}

С 18 по 21 мая Европейское математическое общество и СПбМО проводили в Петербурге тре- 
тью сессию "Европейских лекций по математике". Сессия представляет собой серию из нескольких лекций, посвященных недавнему прогрессу в какой-либо актуальной области математики и прочитанных в каждом из трех различных университетах Европы. Лектор выбрается на конкурсной основе исполкомом Европейского Математического Общества; университеты, где читаются лекции, также отбираются в зависимости от тематики лекций. Такие сессии проводятся раз в два года. В 1999 году в качестве лектора был избран М. Ю. Люьич (Stony Brook, США), получивший хорошо известные результаты в голоморфной и одномерной динамике, а местами прочтения лекций - Санкт-Петербург, Копенгаген и Барселона.

1. Заседание 18 мая 1999 г. (совместное заседание СПбМО и секции математики Дома Ученых). 1-я лекция. Универсальность Фейгенбаума и динамика квадратичных многочленов.

Закон универсальности Фейгенбаума, открытый около двадщати лет назад, поразил как физиков, так и математиков. С точки зрения физики, он предсказьвает значение параметра перехода от "ламинарного" к "турбулентному" режиму. Математическая сторона представляет серьёзную проблему на стыке теории динамических систем, анализа и геометрии. В докладе рассказано о математических структурах, лежащих в основе этой проблемы, которые недавно привели к ее решению.

2. Заседание 19 мая 1999 г. (семинар по теории представлений и динамическим системам). 2-я лекция. Эргодическая теория вешественных квадратичных отображений.

3. Заседание 20 мая 1999 г. (общеинститутский семинар ПОМИ). 3-я лекция. Голоморфная динамика и гиперболические слоения.

Заседание 25 мая 1999 г. Приобшение школы к мировой математической культуре.

Заседание посвящено новым инициативам в области привлечения молодежи к занятиям математикой. Было сообщено об итогах очередного конкурса-игры Кенгуру. Обсуждался проект международной программы издания научно-популярной литературы. Помимо организаторов заседания (академика РАО М. И. БАшМАКОВА и доцента А. И. ПлОТКИНА) выступили гости из Томска (проф. Э. ГЕЛЬфмАн) и Англии (проф. А. БЕЛЛ, Ноттингем). Состоялась краткая дискуссия. Заседание было посвящено памяти замечательного организатора работы со школьниками Николая Борисовича Василева.

Заседание 1 июня 1999 г. P. CARTIER (France). Интегрируемые дифференциальные уравнения и комбинаторика многогранников.

Изучается асимптотика решений уравнения Книжника-Замолодчикова при помощи соответствующей компактифокикации подходящего вещественного симплекса. Это приводит к так называемому многограннику Stasheff'a, обладающему богатой комбинаторикой. Было также рассказано о приложениях к теории представлений группы кос и алгебр Гекке.

\section{Математический лекторий для студентов}

22 октября 1998 г. А. И. ГЕНЕРАЛОв. Гомологическая алгебра с точки зрения элементарной алгебры.

6 апреля 1999 г. Н. Ю. НЕЦВЕТАЕВ. $2 \times 2=4$ и континуум гладких структур на четырехмерном пространстве.

21 мая 1999 г. М. Ю. ЛюБич. Множество Мандельброта и проблема жесткости.

\section{Премия общества "Молодому математику" за 1998 год}

Премии удостоены Н. В. ЦилЕвич за работы по теории мер Пуассона-Дирихлеи А. Б. Пушницкий за работы по функциям спектрального сдвига.

Далее следует отчет за первую половину 2002 года.

Заседание 22 января 2002 г. В. Е. Корепин (Stony Brook, США). Квантовые компьютеры.

В докладе были рассмотрены квантовая телепортация и алгоритм Дойча. 
Заседание 26 февраля 2002 г. С. Г. КРыЖЕВиЧ. Об усилении некоторых классических результатов теории устойчивости.

Известны классические резултаты Ляпунова, Перрона и других авторов об условной устойчивости решений дифференциальных систем по первому приближению и об асимптотических свойствах решений в зависимости от линейной части и нелинейности. Докладчиком введены классы так называемых слабо гиперболичных линейных систем, включающие в себя как правильные, так и гиперболические системы. Получены теоремы об условной устойчивости решений в зависимости от коэффициентов слабой гиперболичности линейной части и порядка малости нелинейного возмущения. Эти результаты являются обобщением теорем Ляпунова и Перрона.

Заседание 2 апреля 2002 г. А. И. НЕЙштАДт (Москва). О затягивании потери устойчивости при динамических бифуркациях.

Затягивание потери устойчивости - интересное, важное и не до конца еще понятное явление в динамике систем с медленно изменяющимися параметрами. Оно состоит в следующем.

Пусть система, зависящая от параметра, имеет при каждом фиксированном значении параметра невырожденное равновесие. Пусть при каком-то критическом значении параметра это равновесие теряет устойчивость: при значениях параметра, меньших критического, равновесие асимптотически устойчиво в линейном приближении, а при значениях параметра, болшших критического - неустойчиво. Добавим к задаче динамику самого параметра: пусть он медленно растет со временем и проходит через указанное критическое значение. Оказьвается, что если система аналитична, то потеря устойчивости неизбежно затягивается: притянувшаяся к равновесию при значениях параметра, меньших критического, система остается в окрестности потерявшего устойчивость положения равновесия еще долгоевремя, за которое параметр успевает измениться на конечную величину, не зависящую от скорости изменения параметра.

Это затягивание потери устойчивости - свойство именно аналитических систем, в типичных бесконечно дифференцируемых системах срыв с потерявшего устойчивость равновесия происходит вблизи критического значения параметра. Так что в явлении затягивания материализуется отличие аналитических систем от бесконечно дифференцируемых. Затягивание разрушается очень мальм шумом; тем не менее оно наблюдается в компьютерных и реальных экспериментах.

Заседание 8 апреля 2002 г. Совместное заседание общества и Общего семинара ПОМИ.

Ю. С. Ильяшенко (Москва). Инфинитезимальная 16-я проблема Гильберта.

Проблема состоит в оценке числа предельных циклов полиномиальных векторных полей, близких к интегрируемым. Основная задача связана с оценкой числа нулей абелевых интегралов от полиномиальных 1-фформ по овалам вещественного многочлена на плоскости. Эта задача, лежащая на границе между алгебраической геометрией, комплексным анализом и дифференциальными уравнениями, исследовалась многими авторами: Ю. Ильяшенко (1969), Г. Петровым, А. Варченко, А. Хованским (80-е годы), Д. Новиковым, С. Яковенко (90-е). В докладе рассказано об этих исследованиях, а также о недавней работе А. Глуцюка и докладчика.

Заседание 23 апреля 2002 г. Дискуссия о планируюшейся реформе школьного образования.

Не отрицая необходимость улучшения школьного и, не в последнюю очередь, математического образования, участники заседания высказали серьёзную обеспокоенность возможным разрушительным эффектом реформы, которая разрабатьвается без привлечения ведущих учёных.

На заседании выступили А. М. АбРАмов (МосквА), Б. М. МакаРов, М. И. БАшмАкОВ, В. А. РЫЖИК, Н. Н. УДАЛЬЦОВА, А. Л. ВЕРНЕР, А. М. ВЕРШИК, Ю. В. МАТИЯСЕВич, А. А. Лодкин. Документы, имеющие отношение к конференции, помещены на странице http://www.mathsoc.spb.ru/forum/reform02.html.

Резолюция заседания. 23 апреля 2002 года состоялось заседание Санкт-Петербургского математического общества, посвященное обсуждению планирующейся реформы школьного образования. В заседании приняли участие известные математики и педагоги города. Собравшиеся выразили серьезную обеспокоенность в связи с документами, определяющими реф̆орму образования.

Вызьвают возражения узко ведомственньй состав группы разработчиков и поспешность, с которой Министерство образования намерено претворять эти предложения в жизнь, затрачивая значительные средства на широкомасштабный эксперимент, результат которого, скорее всего, 
предрешен. Участники заседания отметили также недопустимо низкий уровень разработанных методических документов по математике.

Опубликованные документы свидетельствуют, что при коренном реформировании нашей школы, справедливо считающейся одной из лучших в мире, министерство ориентируется в основном на опыт американской системы образования, весьма отличной от нашей. Как видно из разработанных документов (и это уже отмечалось, в частности, в резолюциях Отделения ядерной физики РАН, Московского математического общества и ученого совета Математического института РАН), их авторы фактически настаивают на необходимости резкого снижения уровня знаний оканчивающих среднюю школу. Не ограничиваясь этим, они предлагают даже внести соответствующие поправки в Закон Р $\Phi$ об образовании и устранить само содержащееся в нем понятие "обязательный минимум содержания образования". Участники заседания выразили опасение, что столь радикалшная реформа нашей школы может привести лишь к повсеместному резкому падению уровня среднего образования в России. Такое развитие событий необходимо предотвратить.

Собрание считает необходимым сделать следующее.

1. Признать неправильным, что такое затрагивающее всех членов общества мероприятие как радикальная реформа среднего образования начинает осуществляться без широкого обсуждения, на основе односторонних, поспешных и келейно принятых решений. Это тем более недопустимо, что Закон РФ об образовании (статья 1 , пункт 3 , и статья 7 , пункт 5 ) требует, чтобы программы развития образования, государственные образовательные стандарты и их изменения разрабатьвались на конкурсной основе.

2. Немедленно объявить мораторий на проведение начинающегося широкомасштабного эксперимента по реформе среднего образования.

3. Обратиться к Президиуму РАН с предложением создать комиссию из членов различных отделений академии с приглашением представителей ведущих университетов, педагогических университетов, РАО, АМН, учителей и общественности для изучения современного состояния среднего образования и возможных направлений его реформирования, учитьвая отечественный и мировой опыт. Организовать широкое обсуждение вьводов и рекомендаций этой комиссии, а также документов, разработанных Министерством образования.

Президент общества доктор физ.-матем. наук, профессор

А. М. Вершик.

Резолюция опубликована в газете "Известия" за 31 мая 2002 г.

Заседание 27 мая 2002 г. Х. ЦишАнГ (Бохум). Минимальные трехмерные многообразия. На совокупности трехмерных многообразий вводится отношение частичного порядка: $M \geq$ $N$, если существует отображение $f: M \rightarrow N$ степени 1 . Многообразие $M$ называется минимальным, если из $M \geq N$ следует, что $N \cong S^{3}$ или $N \cong M$. Общая задача состоит в нахождении минимальных 3 -многообразий или в определении, для данного многообразия, является оно минималшным или нет. Доклад посвящен решению задачи в последней формулировке для пространств Зейферта.

Оказьвается, что кроме проективного пространства имеется еще 7 минимальных линзовых пространств. Кроме того, существует бесконечно много минимальных пространств Зейферта с конечной фундаментальной группой (призмовые многообразия); среди них - гомологическая сфера Пуанкаре, фундаментальная группа которой имеет порядок 120. Среди многообразий Зейферта с бесконечной фундаменталњной группой имеется тоже бесконечно много минималњных. Все они малы в том смысле, что база расслоения Зейферта является сферой и число особых слоев равно 3. Подчеркнем, что у нас нет описания всех минимальных пространств Зейферта, но для заданного многообразия Зейферта мы умеем решать вопрос о минимальности. (Исследования проведены совместно с К. Хайат-Легранд, Ш. Вангом, С.В.Матвеевым.)

Заседание 18 июня 2002 г. В.А. Лифшиц (Остин, США). Стабильные модели логических программ.

Логическая программа - это множество выражений, называемых "правилами". Стабильные модели логической программы определяются как неподвижные точки антимонотонного оператора на множествах атомарных символов, ассоциированного с этой программой. Понятие ста- 
бильной модели было первоначалшно введено для описания поведения системы программирования PROLOG. В последние годы оно привело к разработке нового подхода к решению переборных задач. В докладе показано, как некоторые понятия теории графов могут быть описаны в терминах стабильных моделей.

Заседание 22 июня 2002 г. Совместное заседание общества и Российско-Германской конференции, посвященной 90-летию академика А. Д. Александрова.

Вечер воспоминаний об А. Д. Александрове.

На заседании выступили Ю. Г. РЕшЕТняк, Г. М. ИДлИС, А. Л. ВЕРнЕР, Ю. Ф. БоР ИСОВ, Н. А. ШАНИН, С. С. КУТАТЕЛАДЗЕ, В. Н. БЕРЕСТОВСКИЙ, А. И. НАЗАРОВ, А. М. ВЕРШИК.

\section{Математический лекторий для студентов}

17 апреля 2002 г. В. М. БАБич. Понятие функции в ее становлении.

\section{Премия общества "Молодому математику"}

Премии за 1999 год удостоен Г. Б. МихАлкин за работу "Вещественные алгебраические кривые, отображение моментов и амебы".

Премии за 2000 год удостоен О. Я. ДЕмчЕнкО за работу “Арифметические свойства спаривания Гильберта на формальных группах Хонды”.

Лауреатами премии за 2001 год стали:

С.Г. КрыжЕвич за работы по теории возмущеных линейных систем обыкновенных диффференциальных уравнений;

А. В. МАлютин за работы по группам кос.

\section{“Труды" и препринты общества}

В “Трудах Санкт-Петербургского математического общества" публикуются статьи обзорного характера, научные статьи, посвященные изложению новых результатов, и очерки по истории математики. В 1998-2001 гг. вышли тома 5-8. Почти одновременно появляются английские переводы, издаваемые AMS. Статьи принимаются как от членов общества (в первую очередь), так и от других математиков (подробности и правила для авторов см. на сайте общества по адресу http://www.mathsoc.spb.ru/rus/trudyr.html).

В феврале 1999 г. организован электронньй архив препринтов общества: http://www.mathsoc.spb.ru/preprint. Тексты принимаются по адресу pmo-prep@pdmi.ras.ru. Ссылки на препринты доступны поисковой системе MPRESS сервера http://euler.zblmath.fiz-karlsruhe.de/MPRESS Европейской математической информационной службы EMIS.

\section{Сайт общества}

C 1996 г. существует сайт общества http://www.mathsoc.spb.ru/rus, которьй содержит обширную информацию:

- об обществе, его истории и текущей деятельности, о выдающихся математиках, чья деятельность связана с Петербургом-Ленинградом;

- о городских семинарах и предстоящих конференциях;

- о вакансиях для математиков в Петербурге и за рубежом;

- список членов общества (со ссылками на персональные страницы в Интернете);

- уже упомянутый архив препринтов.

Время от времени сайт общества предоставляется для дискуссий по злободневным вопросам математической жизни. 